\title{
Combined use of anti-ErbB monoclonal antibodies and erlotinib enhances antibody-dependent cellular cytotoxicity of wild-type erlotinib-sensitive NSCLC cell lines
}

\author{
Andrea Cavazzoni ${ }^{1 \dagger}$, Roberta R Alfieri ${ }^{1{ }^{*}+}$, Daniele Cretella ${ }^{1}$, Francesca Saccani ${ }^{1}$, Luca Ampollini ${ }^{2}$, Maricla Galetti ${ }^{1,3}$, \\ Federico Quaini ${ }^{1}$, Gallia Graiani ${ }^{1}$, Denise Madeddu', Paola Mozzoni ${ }^{1,3}$, Elena Galvani ${ }^{1}$, Silvia La Monica ${ }^{1}$, \\ Mara Bonelli', Claudia Fumarola ${ }^{1}$, Antonio Mutti ${ }^{1}$, Paolo Carbognani ${ }^{2}$, Marcello Tiseo ${ }^{4}$, Elisabetta Barocelli ${ }^{5}$, \\ Pier Giorgio Petronini ${ }^{1}$ and Andrea Ardizzoni ${ }^{4}$
}

\begin{abstract}
Background: The epidermal growth factor receptor (EGFR) is an established target for anti-cancer treatment in different tumour types. Two different strategies have been explored to inhibit this pivotal molecule in epithelial cancer development: small molecules TKIs and monoclonal antibodies. ErbB/HER-targeting by monoclonal antibodies such as cetuximab and trastuzumab or tyrosine-kinase inhibitors as gefitinib or erlotinib has been proven effective in the treatment of advanced NSCLC.

Results: In this study we explored the potential of combining either erlotinib with cetuximab or trastuzumab to improve the efficacy of EGFR targeted therapy in EGFR wild-type NSCLC cell lines. Erlotinib treatment was observed to increase EGFR and/or HER2 expression at the plasma membrane level only in NSCLC cell lines sensitive to the drug inducing protein stabilization. The combined treatment had marginal effect on cell proliferation but markedly increased antibody-dependent, NK mediated, cytotoxicity in vitro. Moreover, in the Calu-3 xenograft model, the combination significantly inhibited tumour growth when compared with erlotinib and cetuximab alone.

Conclusion: Our results indicate that erlotinib increases surface expression of EGFR and/or HER2 only in EGFR-TKI sensitive NSCLC cell lines and, in turns, leads to increased susceptibility to ADCC both in vitro and in a xenograft models. The combination of erlotinib with monoclonal antibodies represents a potential strategy to improve the treatment of wild-type EGFR NSCLC patients sensitive to erlotinib.
\end{abstract}

Keywords: Lung cancer, EGFR, Erlotinib, Cetuximab, ADCC

\section{Background}

The epidermal growth factor receptor (EGFR, ErbB1, HER1) is the prototypic member of the ErbB family of receptor tyrosine kinases (TKs), which further consists of ErbB2-4 (HER2-4). The ErbB receptors share a similar protein structure, consisting of an extracellular ligand binding domain, a single transmembrane domain and an

\footnotetext{
* Correspondence: roberta.alfieri@unipr.it

${ }^{\dagger}$ Equal contributors

'Department of Clinical and Experimental Medicine, University of Parma, Parma, Italy

Full list of author information is available at the end of the article
}

intracellular C-terminal domain with tyrosine kinase activity [1]. Upon specific binding of EGF-like ligands to the extracellular domain, ErbB receptors dimerize, either as homo- or heterodimers, and undergo autophosphorylation at specific tyrosine residues within the intracellular domain. The phosphorylated tyrosines serve as docking sites for adapter molecules, such as Grb2 and the p85 subunit of PI3K, which activate a complex downstream network. The activated signaling pathways, including the Ras/MAPK, Akt/mTOR kinase and STAT cascades, in turn regulate transcription factors and other proteins involved in cell proliferation, survival, motility 
and differentiation [2]. Two main strategies targeting ErbB receptors have been developed: small-molecule inhibitors of the tyrosine kinase domain (EGFR tyrosine kinase inhibitors [TKIs], such as erlotinib and gefitinib), and monoclonal antibodies (such as cetuximab, antiEGFR and trastuzumab, anti-HER2), directed against the extracellular domain, which inhibit phosphorylation/ activation and promote internalization. EGFR and HER2 are overexpressed in $40-80 \%$ and $25-30 \%$, respectively, of non-small cell lung cancer (NSCLC) patients and their overexpression has been frequently correlated with a poor prognosis [3,4].

Erlotinib is an effective treatment for NSCLC patients and has been registered as a second and third-line treatment of NSCLC regardless of EGFR mutation status [5].

Gefitinib has been registered for the therapy of advanced NSCLC harbouring activating EGFR mutations in the tyrosine kinase domain, the most frequent being L858R in exon 21 and Del (746-750) in exon 19 [6]. Although mutations in EGFR are useful predictors for the activity of EGFR-TKI, they cannot be used as the only criterion to determine who should receive antiEGFR therapy and it is becoming increasingly clear that even patients with EGFR wild-type can benefit from EGFR-TKI $[5,7,8]$.

Cetuximab is a chimeric IgG1 monoclonal antibody (mAb) that blocks ligand binding to EGFR, leading to a decrease in receptor dimerization, autophosphorylation, and activation of signaling pathways [9]. In addition the binding of cetuximab initiates EGFR internalization and degradation which leads to signal termination. Moreover, unlike EGFR-TKIs, cetuximab can induce antibody dependent cellular cytotoxicity (ADCC) activity, an important immunologic antitumour effect. Cetuximab in combination with chemotherapy has been approved by the FDA for the treatment of metastatic colorectal cancer and of locally advanced head and neck cancer.

Two randomized phase III trials in NSCLC patients, evaluating cetuximab in addition to first-line chemotherapy, showed a small benefit in overall survival for the experimental treatment, which was considered insufficient by the EMA for marketing approval [10,11]. However, a subgroup analysis of the FLEX phase III trial recently demonstrated a larger survival benefit from the experimental treatment in patients with high immunohistochemical EGFR expression [12].

Trastuzumab, registered for the treatment of HER2 positive breast cancer, has also been tested in phase II trials as a single agent and in combination with cytotoxic chemotherapy for patients with NSCLC. These trials have not yet produced any convincing evidence of an improved antitumour activity by adding trastuzumab to standard chemotherapy in NSCLC $[13,14]$.
Several preclinical studies on cell lines from different tumour types, indicated that the association between EGFR/HER2 mAbs with TKIs displays an increased efficacy [15].

In this study we explored the potential of combining erlotinib with either cetuximab or trastuzumab in order to improve the efficacy of EGFR targeted therapy in EGFR wild-type sensitive NSCLC cell lines. Our results indicate that EGFR-TKI increases surface expression of EGFR and/or HER2 only in erlotinib sensitive NSCLC cell lines and, in turns, leads to increased susceptibility to ADCC both in vitro and in xenograft models.

\section{Results}

\section{Differential effects of erlotinib on EGFR and HER2} expression in sensitive and resistant NSCLC cell lines

Firstly, we evaluated the effect of erlotinib on total EGFR and HER2 protein levels in sensitive NSCLC cell lines (Calu-3, H322 and H292 cell lines carrying wild-type EGFR; PC9 and HCC827 carrying EGFR E746-A750del mutation) and in resistant cell lines (A549, H1299, H1703 and Calu-1 intrinsically resistant carrying wildtype EGFR; HCC827GR5 with MET amplification as mechanism of acquired resistance to TKI) [16]. As shown in Figure 1A, erlotinib induced accumulation of EGFR protein in Calu-3 and H322 cells while HER2 accumulated in $\mathrm{H} 322, \mathrm{H} 292$, PC9 and HCC827 cells in a dose-dependent manner. The EGFR/Actin and HER2/ Actin ratios obtained after treatment at $1 \mu \mathrm{M}$ or $10 \mathrm{nM}$ erlotinib were calculated and values expressed as fold differences versus control (Figure 1B). In contrast, EGFR and HER2 protein accumulation was not observed in any cancer cell line with intrinsic resistance to EGFR inhibitors until the concentration of $10 \mu \mathrm{M}$. Indeed the ratios EGFR/Actin or HER2/Actin were similar or even lower than those calculated in untreated cells (Figure 1C) and similar results were obtained with gefitinib (not shown). A representative Western blotting of resistant H1299 cell line is reported in Figure 1D.

The different effect of TKIs on HER2 expression between sensitive and resistant NSCLC cell lines was confirmed in the HCC827 parental and in the HCC827GR5 resistant clone treated for $48 \mathrm{~h}$ with gefitinib (Figure 1E).

\section{Erlotinib increases the cell surface expression of EGFR and HER2 in erlotinib sensitive NSCLC cell lines}

EGFR and HER2 expression on the plasma membrane was quantified by flow cytometry in sensitive EGFR wild-type NSCLC cell lines Calu-3, H322 and H292 after exposure to $1 \mu \mathrm{M}$ erlotinib for $24 \mathrm{~h}$. The drug enhanced surface expression, calculated as molecules of equivalent soluble fluorophore, of EGFR in Calu-3 (Figure 2A) and H322 (Figure 2C, 2D) and of HER2 in H292 (Figure 2B) and H322 (Figure 2C, 2D) cell lines. In H322 cell line, 
A

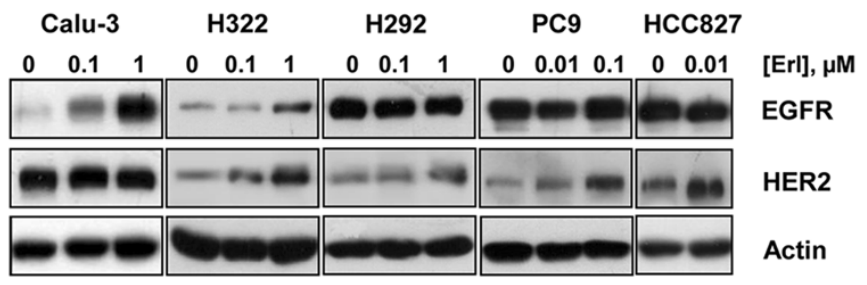

B

\begin{tabular}{|c|c|c|c|c|}
\hline $\begin{array}{c}\text { Sensitive } \\
\text { NSCLC } \\
\text { cell lines }\end{array}$ & EGFR & RAS & EGFR/Actin & HER2/Actin \\
\hline CALU-3 & WT & WT & 5.8 & 1 \\
\hline H322 & WT & WT & 2.4 & 2.5 \\
\hline H292 & WT & WT & 1 & 1.6 \\
\hline PC9 & $\begin{array}{c}\text { Mut } \\
\text { (E746A750del) }\end{array}$ & WT & 1 & 2.1 \\
\hline HCC827 & $\begin{array}{c}\text { Mut } \\
\text { (E746A750del) }\end{array}$ & WT & 1 & 1.5 \\
\hline
\end{tabular}

C

\begin{tabular}{|c|c|c|c|c|}
\hline $\begin{array}{c}\text { Resistant } \\
\text { NSCLC } \\
\text { cell lines }\end{array}$ & EGFR & RAS & EGFR/Actin & HER2/Actin \\
\hline $\begin{array}{c}\text { HCC827 } \\
\text { GR5 }\end{array}$ & $\begin{array}{c}\text { Mut } \\
\text { (E746A750del) }\end{array}$ & WT & 1 & 1.1 \\
\hline A549 & WT & G12S & 1.2 & 1 \\
\hline H1299 & WT & Q61K & 1 & 1 \\
\hline H1703 & WT & WT & 0.9 & 0.9 \\
\hline Calu-1 & WT & G12S & 0.6 & 0.7 \\
\hline
\end{tabular}

D

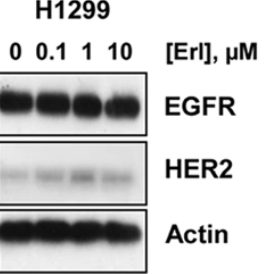

E

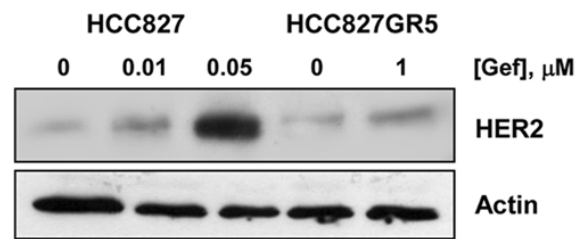


(See figure on previous page.)

Figure 1 Erlotinib induces EGFR and HER2 protein accumulation only in sensitive NSCLC cell lines. (A) Calu-3, H322, H292, PC9 and HCC827 cell lines were treated with the indicated concentrations of erlotinib for $48 \mathrm{~h}$. At the end of the drug treatment cell lysates were immunoblotted to detect the indicated proteins. The immunoreactive spots were quantified by densitometric analysis, ratios of EGFR/Actin and HER2/Actin were calculated at 1 MM erlotinib for Calu-3 H322 and H292 or 10 nM for PC9 and HCC827 and values are expressed as fold increase versus control (B). (C) HCC827GR5, A549, H1299, H1703, Calu-1 cell lines were treated with 1 MM erlotinib for $48 \mathrm{~h}$ and at the end of treatment cell lysates were immunoblotted to detect the indicated proteins. The immunoreactive spots were quantified by densitometric analysis, ratios of EGFR/Actin and HER2/Actin were calculated and values are expressed as fold increase versus control. (D) Representative Western blotting of resistant H1299 cell line exposed to increased concentration of erlotinib. (E) HCC827 parental cell line and HCC827GR5 resistant clone were treated with the indicated doses of gefitinib and processed as above. The results are from representative experiments. Each experiment, repeated three times, yielded similar results.

the increase in EGFR and HER2 surface expression was dose and time dependent (Figure 2C, 2D). Western blot analysis of isolated cell surface membrane proteins (inset Figure 2A) confirmed the increase of EGFR in erlotinib treated Calu-3 cells.

Exploiting the ability of cetuximab and trastuzumab to bind EGFR and HER2, we used these mAbs as primary antibodies for flow cytometry analysis. By this approach, as shown in Figure 3, we confirmed that the surface density of cetuximab and trastuzumab-binding sites, respectively, on Calu-3 (Figure 3A), H322 (3B) and H292 (3C) cells were increased after $1 \mu \mathrm{M}$ erlotinib treatment. These results suggest that erlotinib enhanced cell surface expression of EGFR or HER2 on sensitive NSCLC cells, leading to an increase of mAbs binding to cancer cell surface.

\section{Erlotinib induces EGFR protein stabilization}

The possibility that the higher EGFR level observed in Calu-3 cells exposed to erlotinib was due to protein stabilization or increased synthesis was then explored. As shown in Figure 4A, EGFR level increased after $2 \mathrm{~h}$ of erlotinib treatment and reached a plateau after $24 \mathrm{~h}$. Furthermore, the maximum level was maintained during time in the presence of the drug. However, after $48 \mathrm{~h}$ of erlotinib removal, EGFR expression was reduced to level
A

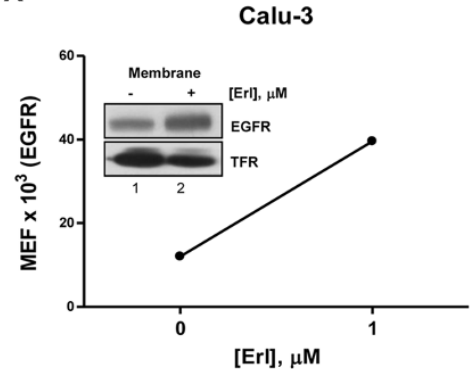

C

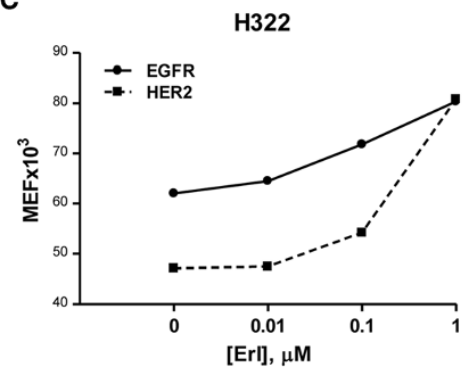

B

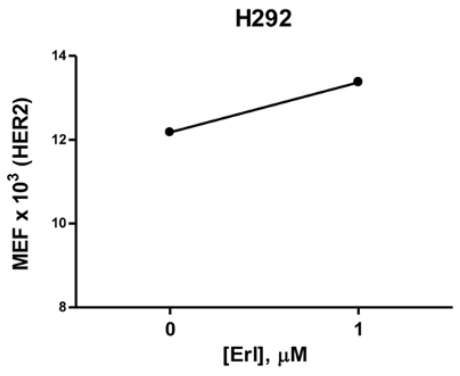

D

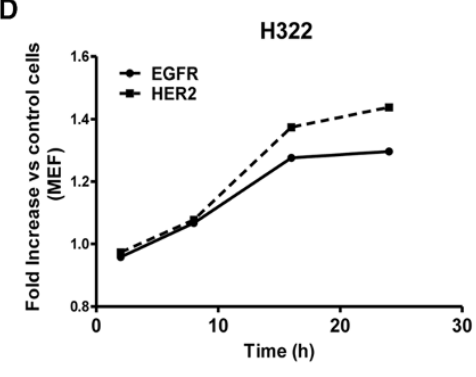

Figure 2 EGFR and HER2 increase at the plasma-membrane level. Calu-3 (A) and H292 (B) cell lines were treated with $1 \mu \mathrm{M}$ erlotinib for $24 \mathrm{~h}, \mathrm{H} 322$ cell line was treated with increasing concentration of erlotinib (C) or with $1 \mu \mathrm{M}$ erlotinib for the indicated period of time (D). At the end of the treatment, cell surface expression of EGFR and/or HER2 were evaluated by flow cytometry and the quantification is reported as Molecules of Equivalent Fluorophore [MEF] or as fold increase versus untreated control cells (D). Inset Figure 2A: Western blot analysis of EGFR protein membrane level in Calu-3 after treatment with $1 \mu \mathrm{M}$ erlotinib for $24 \mathrm{~h}$. Whole cells were labeled with biotin and membrane bound proteins were pulled down with neutrAvidin beads. The results are from representative experiments. Each experiment, repeated three times, yielded similar results. 


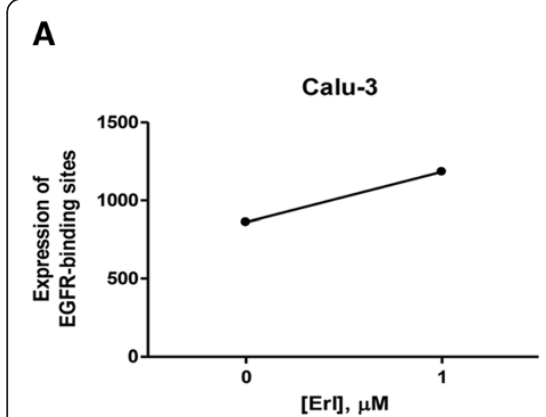

B

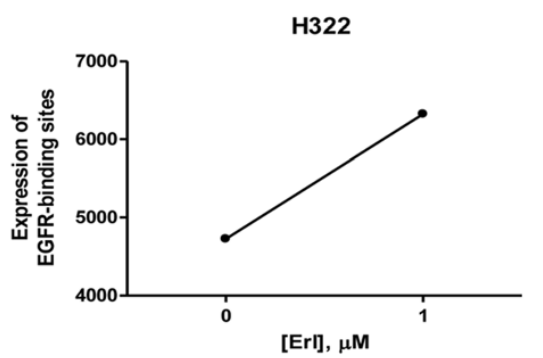

C

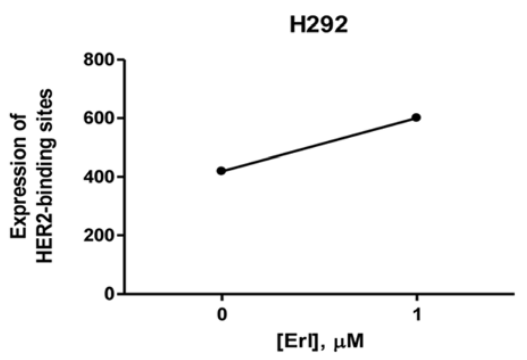

Figure 3 Erlotinib induces the increase of cetuximab and trastuzumab binding sites. Calu-3, H322 and H292 cell lines were treated with erlotinib for $24 \mathrm{~h}$. Binding sites were assessed by flow cytometry using cetuximab (Calu-3, H322) and trastuzumab (H292) as primary antibodies followed by PE-anti-human IgG exposure. Binding sites quantification is reported as Molecules of Equivalent Fluorophore [MEF]. The results in $\mathbf{A}$, B, C are from representative experiments. Each experiment, repeated three times, yielded similar results.

comparable to untreated cells (Figure 4B). Calu-3 were also treated with erlotinib in the presence of specific inhibitors of mRNA (Actynomicin D) and protein (Cycloheximide) synthesis. As shown in Figure 4C, the erlotinib- induced EGFR protein increase was neither influenced by Actynomicin D nor Cycloheximide treatment indicating that the higher level of EGFR after erlotinib treatment could be ascribed to post-transcriptional mechanisms such as protein stabilization. Moreover, we analyzed EGFR transcript level by real time PCR after erlotinib treatment (Figure 4D). Erlotinib did not affect EGFR mRNA level when compared to untreated cells.

With the aim to clarify why the increased level of EGFR was induced only in sensitive cells, we then tested the effect of EGFR inhibitors (gefitinib, erlotinib, cetuximab, lapatinib) and of inhibitors of MAPK and PI3K/
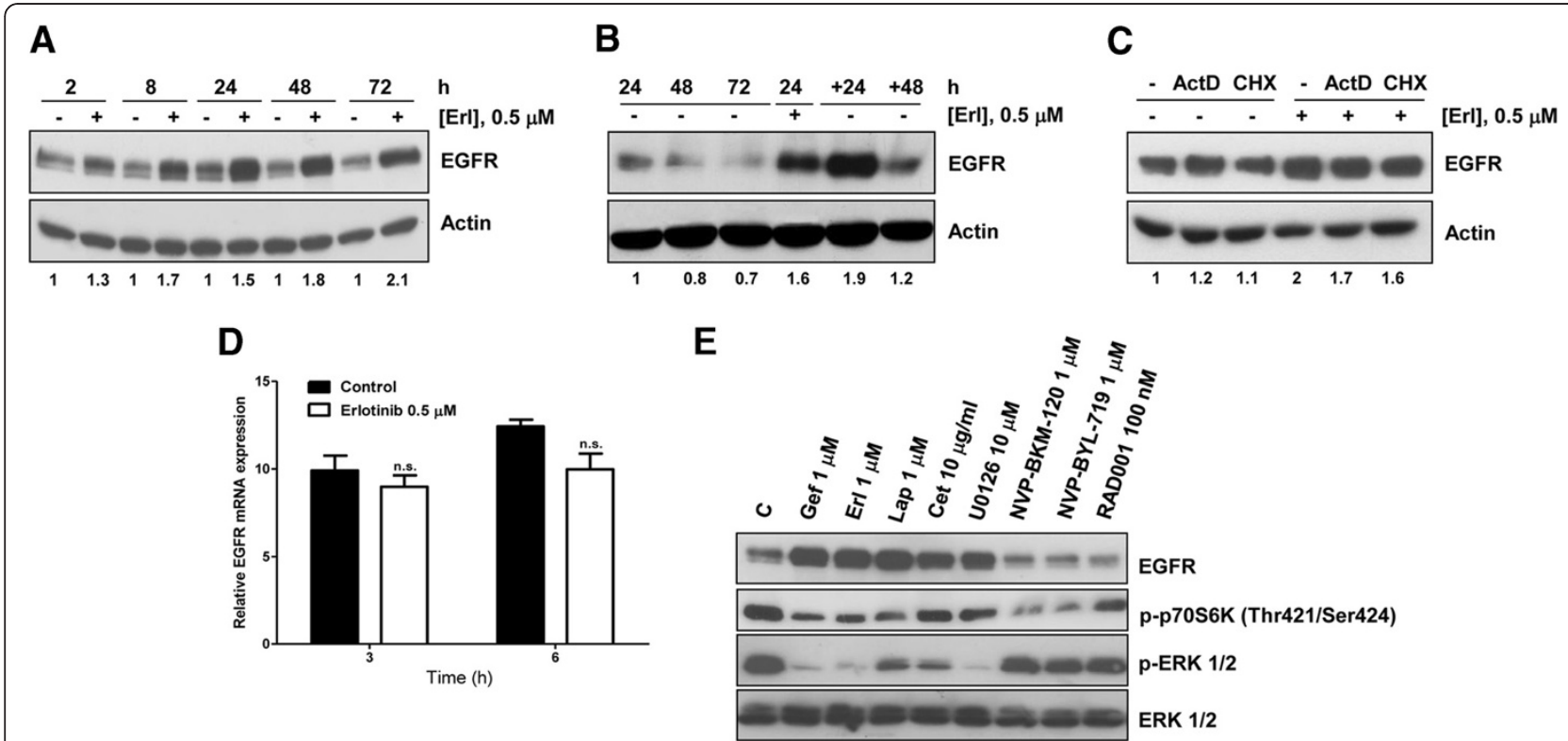

Figure 4 Erlotinib induces EGFR protein accumulation through protein stabilization. (A) Calu-3 cells were treated for the indicated period of time with $0.5 \mu \mathrm{M}$ erlotinib. At the end of drug treatments cell lysates were immunoblotted to detect EGFR protein. (B) Calu-3 cells were treated with $0.5 \mu \mathrm{M}$ erlotinib for $24 \mathrm{~h}$ then the drug was removed and drug-free medium was added for further 24 and $48 \mathrm{~h}$. Then, cell lysates were immunoblotted to detect the EGFR protein levels. (C) Calu-3 cells were treated for $24 \mathrm{~h}$ with erlotinib $0.5 \mu \mathrm{M}$, in the absence/presence of $0.1 \mu \mathrm{g} / \mathrm{ml}$ actynomicin $\mathrm{D}$ and $2 \mu \mathrm{g} / \mathrm{ml}$ cyclohexymide. At the end of the experiment, cell lysates were immunoblotted to detect the indicated proteins. The immunoreactive spots were quantified by densitometric analysis, ratios of EGFR/Actin were calculated and values are expressed as fold increase versus control. (D) Calu-3 cells were exposed to $0.5 \mu \mathrm{M}$ erlotinib for the indicated period of time and the EGFR mRNA was detected by RT-PCR. The mean values of two independent measurements ( \pm SD) are shown. (E) EGFR, p-P70S6K, p-P44/42 and P44/42 were detected by Western blotting in Calu-3 cells untreated or treated for $24 \mathrm{~h}$ with $1 \mu \mathrm{M}$ gefitinib, erlotinib and lapatinib, $10 \mu \mathrm{g} / \mathrm{ml}$ cetuximab, $10 \mu \mathrm{M} \cup 0126,1$ HM NVP-BKM-120 and NVP-BYL-719 and 100 nM RAD001. The results are from representative experiments. Each experiment, repeated three times, yielded similar results. 
$\mathrm{AKT} / \mathrm{mTOR}$ signaling transduction pathways on EGFR accumulation in Calu-3 cell line. Gefitinib, erlotinib, lapatinib significantly inhibited the phosphorylation of p70S6K and p44/42 and induced a significant increase in EGFR protein level (Figure 4E). The MEK inhibitor U0126 strongly enhanced EGFR expression, in contrast no increase in the EGFR level was observed after incubation with the inhibitors of PI3K/AKT/mTOR pathway tested (NVP-BKM-120 and NVP-BYL-719 PI3K inhibitors and RAD001 mTOR inhibitor).

\section{Effects of erlotinib and cetuximab combined treatment on NSCLC cell growth and antibody-dependent cell-mediated cytotoxicity}

We then investigated the effect of targeting EGFR by both the TKI erlotinib and the mAb cetuximab in a cell viability assay (Figure 5). We treated Calu-3, H322 and H1299 cells with erlotinib, cetuximab (doses ranged from 1 to $50 \mu \mathrm{g} / \mathrm{ml}$ ) or the combination based on the schedule erlotinib $24 \mathrm{~h}$ followed by the combination of erlotinib with cetuximab for 72 h. As expected Calu-3 (Figure 5A) and H322 (Figure 5B) cells were responsive to erlotinib and cetuximab treatment, whereas H1299
(Figure 5C) cells were resistant to both the single regimens. Comparing the experimental combination points with that expected by the Bliss criterion, an additive effect was observed only in the Calu-3 cells. In fact, in the H322 cells we failed to observe any improvement treating cells with the combined treatment and H1299 remained resistant.

Moreover, cell death, evaluated by morphological analysis, caspase- 3 activation and cleavage, was negligible under any of the tested treatments at all the time points analyzed (not shown) suggesting that the combined erlotinib-cetuximab treatment exerted a cytostatic and not a cytotoxic effect.

Since the engagement of immune component system is one of the main mechanisms of the activity of specific mAbs directed to ErbB family members in vivo, we examined whether erlotinib could enhance cetuximabor trastuzumab-mediated ADCC by NK cells. As shown respectively in Figure 6 A-B cetuximab-dependent cytotoxicity in the presence of IL-2 activated NK cells was higher in Calu-3 and H322 cells previously treated with erlotinib compared with cells treated with cetuximab alone. Similarly, trastuzumab-dependent cytotoxicity was

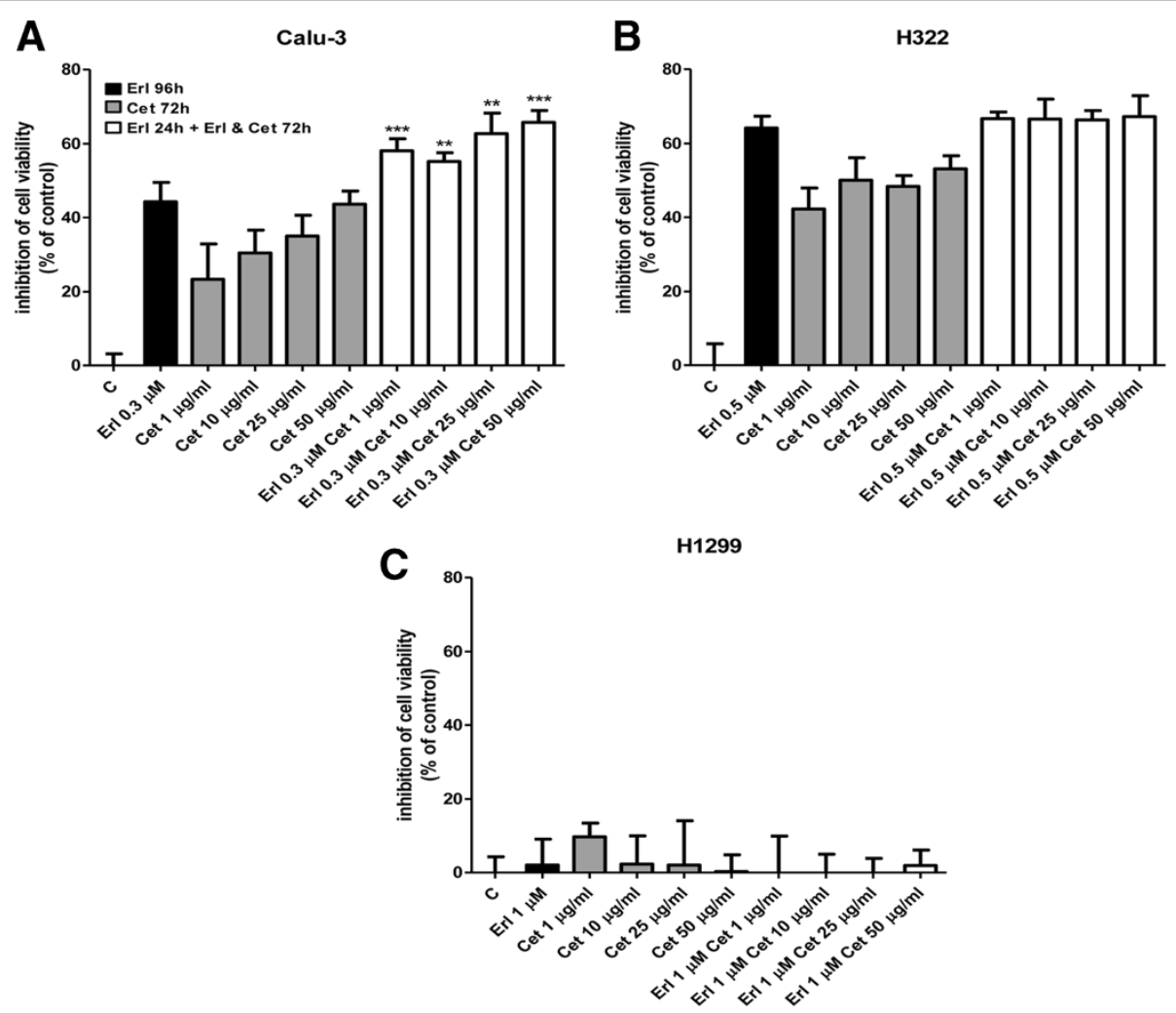

Figure 5 Effect of erlotinib and cetuximab combination on cell viability in NSCLC cell lines. Calu-3, H322 sensitive cells (A, B) and H1299 resistant cells $\mathbf{( C )}$ were exposed to the indicated concentrations of erlotinib for $96 \mathrm{~h}$ or cetuximab for $72 \mathrm{~h}$ and to erlotinib for $24 \mathrm{~h}$ followed by the combination of erlotinib and cetuximab for $72 \mathrm{~h}$. After the treatments, cell viability was assessed by MTT assay. Data are expressed as percent inhibition of cell viability versus control cells and are mean values of three separate experiments (**P $<0.01{ }^{* * *} P<0.001$ ). 

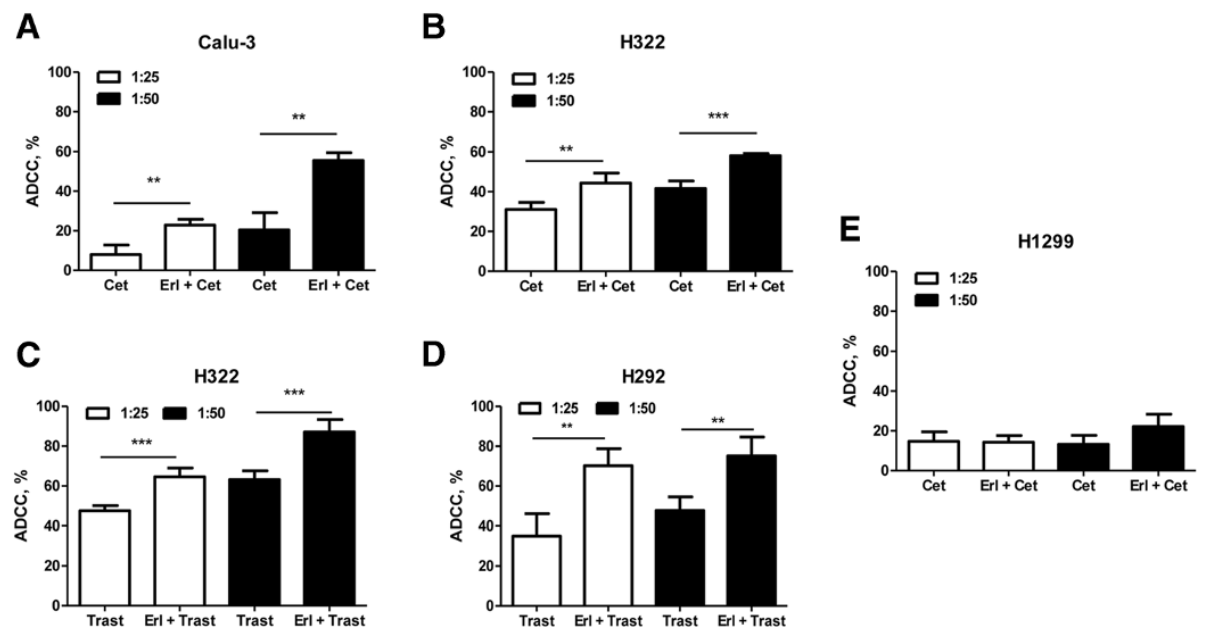

Figure 6 Erlotinib potentiates antibody dependent cell cytotoxicity. The indicated human NSCLC cell lines were treated with $1 \mu$ M erlotinib for $24 \mathrm{~h}$. After the treatment with erlotinib, $10 \mathrm{\mu g} / \mathrm{ml}$ Cetuximab (A, B, E) or Trastuzumab (C, D) were added to cancer cells seeded with $100 \mathrm{U} / \mathrm{ml} \mathrm{IL-2}$ activated-NK cells at the ratio of 1:25 and 1:50. After $4 \mathrm{~h}$ LDH release was determined as described in Methods section. The results are from representative experiments. The experiment, repeated three times, yielded similar results $\left({ }^{* * P}<0.01{ }^{* * *} P<0.001\right)$.

higher in H322 and H292 cells (Figure 6 C-D) previously treated with erlotinib compared with cells treated with trastuzumab alone.

On the contrary, the combination of erlotinib with cetuximab did not significantly modify the mAb dependent cytotoxicity in H1299 resistant cancer cells.
Effect of erlotinib and cetuximab on Calu-3 xenografts

To extend our results in vivo, we tested the combination of erlotinib with cetuximab in a Calu-3 xenograft model (Figure 7). When tumours were well established (14 days post-injection, average volume of $300 \mathrm{~mm}^{3}$ ) mice were randomized into four treatment groups receiving

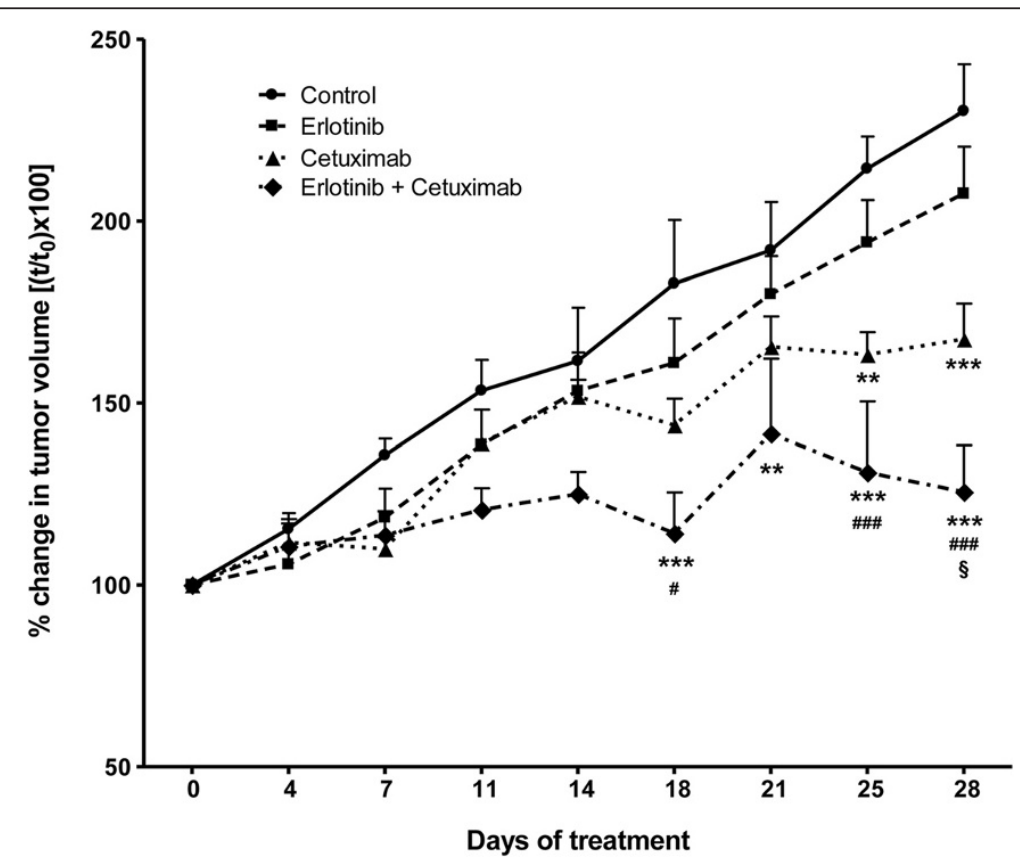

Figure 7 Antitumour activity of erlotinib and cetuximab on Calu-3 xenografts. Calu-3 cells were suspended in matrigel and sterile PBS (1:1) and implanted s.c. (right flank) on female BALB/c-Nude mice. Tumours were allowed to establish growth after implantation for 14 days, and the treatments started when tumours reached an average volume of $300 \mathrm{~mm}^{3}$. Vehicle, erlotinib ( $25 \mathrm{mg} / \mathrm{Kg}$, orally 5 days/week), cetuximab (2 mg/Kg i.p. twice weekly), or erlotinib plus cetuximab were administered for the duration of the study. Data are expressed as percent change in tumour volume \pm SEM of 6 mice per group. ( ${ }^{* *} p<0.01,{ }^{* * *} p<0.001$ vs control; ${ }^{\#} p<0.05,{ }^{* \# \#} p<0.001$ vs erlotinib; ${ }^{\S} p<0.05$ vs cetuximab; two-way ANOVA followed by Bonferroni post-test). 
erlotinib alone, cetuximab alone, the combination, or vehicles as described in the Methods section. Drug treatments were well tolerated, and no signs of toxicity were detected during the study. The treatment with either erlotinib or cetuximab as single agent delayed tumour growth. However, the significance of the treatment versus the control was observed only with cetuximab as single agent or in combination. Interestingly, the treatment with the combination of erlotinib plus cetuximab significantly inhibited tumour growth when compared to both the single agent treatments.

The histologic analysis of tumour samples showed that the subcutaneous injection of Calu- 3 strikingly reproduced within four weeks the morphological features of human adenocarcinoma (Figures 8A, 8B1-4, 8C-1). Neoplastic epithelial cells clearly expressed cytokeratin (Figure $8 \mathrm{C}-2$ ) and were organized in secretory glands surrounded by cellularized collagen as evidenced by Masson's trichrome staining (Figure 8C-4). Regressive phenomena and changes in size of neoplastic glands together with intense stromal reaction were observed in histologic samples of tumours from treated mice. Interestingly, cetuximab clearly resulted in dense inflammatory periglandular infiltrates mostly composed of lymphocytes (Figure 8C-3). Thus, the real impact of treatment on tumour mass within the nodules was assessed by the morphometric analysis of tissue composition. By this quantitative approach, in agreement with gross anatomic measurements, we documented that the combination of erlotinib with cetuximab was the most effective treatment on tumour growth inhibition (Figure 8D).

This contention was further supported by the immunofluorescence analysis of Ki67 labelling on tumour tissues at the end of the experimental protocol (Figure 9). Erlotinib was able to reduce proliferation of neoplastic cytokeratin $^{\text {pos }}$ cells only in association with cetuximab whereas cetuximab had a negative impact on cycling cells also as individual agent. The TUNEL assay indicated that, according with in vitro data, apoptosis was not a significant ongoing cellular event implicated in the effect of different treatments.

We have calculated that $0.026+/-0.016 \%$ neoplastic cells were undergoing apoptosis in untreated tumours.
A

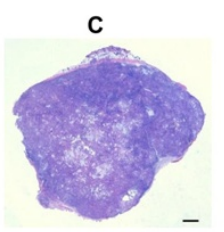

B

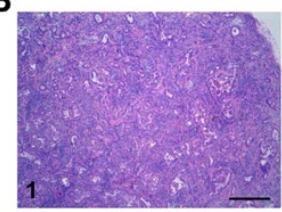

C
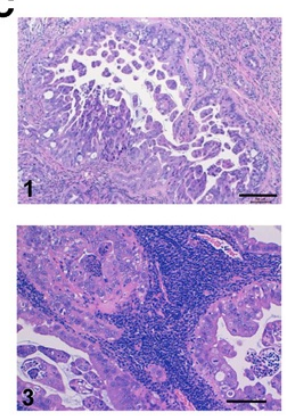
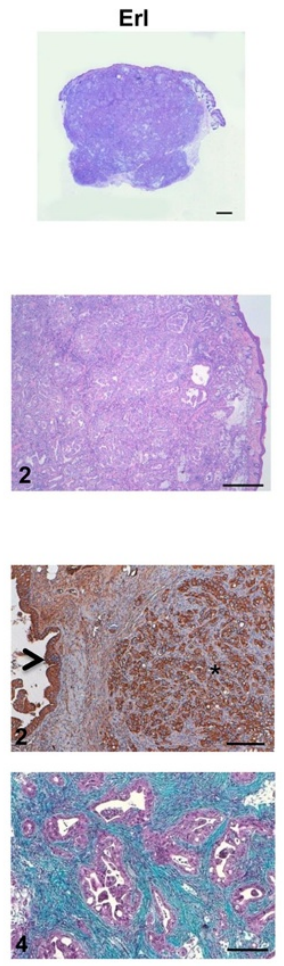
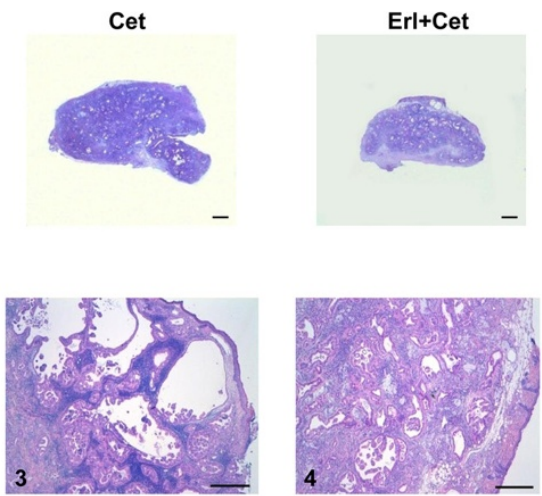

D
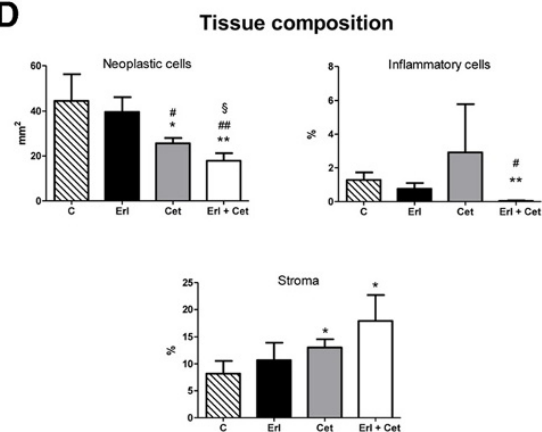

Figure 8 Hystological analysis of tumours. A: Selected examples of H\&E stained sections of the entire subcutaneous xenografted tumour induced by Calu-3 injection in untreated (C) and erlotinib (Erl), cetuximab (Cet) or erlotinib + cetuximab (Erl + Cet) treated BALB/C nude mice (scale bars: $1 \mathrm{~mm}$ ). Higher magnification of the same samples are shown on corresponding panels in B (scale bars: $500 \mu \mathrm{m}$ ). C: representative morphological details of the control neoplastic epithelium (1, H\&E) expressing cytokeratin $\left(2,{ }^{*}\right.$ brown-immunoperoxidase) that also depicts the epidermis (arrowhead). The presence of inflammatory interstitial cells in a cetuximab treated tumour $(3, \mathrm{H \& E})$ and the intense collagen deposition (bluish) surrounding neoplastic glands (purple) in a Erl + Cet treated tumour (4, Masson's trichrome) are shown (scale bars: 100 m). D: Bar graphs illustrating the quantitative measurements of neoplastic, inflammatory cells and stromal compartments composing the tumours. ${ }^{*} p<0.05$, ${ }^{* *} p<0.01$, vs control; $" \mathrm{p}<0.05$, \# $p<0.01$ vs erlotinib; ${ }^{\S} p<0.05$ vs cetuximab). 

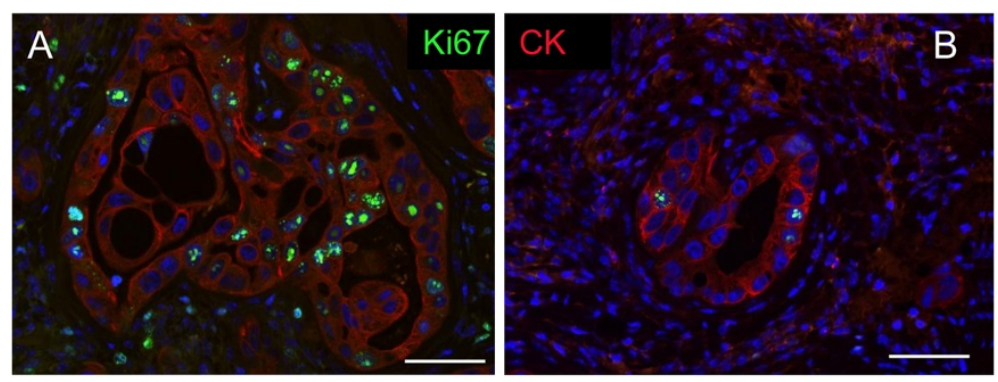

\section{C}

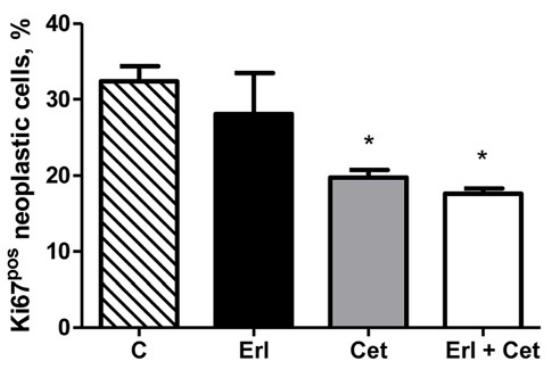

Figure 9 Immunohistochemical analysis of cellular proliferation. Immunofluorescence images of Ki67 (green) nuclear labelling of cytokeratin (CK, red) positive neoplastic cells in sections of xenografted tumours from an untreated (A) and Erl + Cet treated (B) BALB/C nude mouse. C: bar graph illustrating the effect of the different treatments on the percentage of cycling (Ki67pos) neoplastic cells within the tumour. CTRL: untreated, ERL: erlotinib, CET: cetuximab, COMB: erlotinib + cetuximab. * $p<0.01$ vs CTRL.

Similar low numbers were obtained after Erlotinib or Cetuximab single treatment whereas Erl + Cet increased the amount of TUNEL positive neoplastic cells although reaching a rate of $0.12+/-0.03 \%$. However, we cannot exclude that apoptotic cell death may have contributed to the positive effect of tumor shrinkage at earlier times after drug administration.

Thus, these experimental observations suggest that targeting EGFR by the combination of small molecules and antibodies increases the in vitro and in vivo antiproliferative activity of both individual agents and seems to be a potent therapeutic strategy against NSCLC.

\section{Discussion}

The potential for dual-agent molecular targeting of the ErbB family, has been clearly demonstrated in preclinical models and confirmed on the clinical setting for HER2-targeting agents in breast cancer. However, little is known about this therapeutic strategy for different targets in other tumour types.

In our current study we demonstrated that the combination of erlotinib with cetuximab or trastuzumab may enhance the antitumour activity of EGFR-TKI in NSCLC cell lines harbouring wild-type EGFR and in xenograft models.

The efficacy of the association between an EGFR/ HER2 mAbs with TKIs has been documented in preclinical studies in several cell lines originating from different tumour types [15]. In EGFR wild-type H292 and A549 NSCLC cell lines, the combination of either gefitinib or erlotinib with cetuximab was reported to enhance growth inhibition in comparison to single treatment, particularly in the $\mathrm{H} 292$ gefitinib sensitive cell line [17]. In the A549 cell line, expressing both EGFR and HER2, the combination of gefitinib with trastuzumab significantly inhibited cell growth and proliferation [18]. In Calu-3 xenograft models, the combined treatment of erlotinib and pertuzumab showed an enhanced antitumour activity [19].

A correlation between cetuximab efficacy and EGFR expression has been reported in preclinical studies [20] and recently confirmed in clinical trials. Thus, the phase III FLEX study involving patients with advanced NSCLC showed a strong correlation between high tumour EGFR overexpression and the efficacy of adding cetuximab to platinum based first-line chemotherapy [12].

The combination of a TKI and a mAb was explored as a potential strategy to overcome acquired resistance to firstgeneration EGFR-TKIs. Kim and colleagues demonstrated that the combination of lapatinib with cetuximab overcame gefitinib resistance due to the secondary T790M mutation in NSCLC by inducing enhanced cytotoxicity both in vitro and in vivo [21]. Furthermore, the association of cetuximab with afatinib has been shown to be effective to overcome T790M-mediated drug resistance [22]. 
However, the combination of erlotinib with cetuximab did not lead to a significant radiological response in NSCLC patients with clinically defined acquired resistance to erlotinib indicating that such strategy is not sufficient to overcome acquired resistance to erlotinib [23].

The mechanisms leading to an enhanced activity of combining a TKI with a monoclonal antibody have been ascribed, in other cancer cell models, either to a more efficient inhibition of TK receptors [17] or to an increased targeted receptors on plasma membrane induced by TKIs [24,25]. Scaltriti et al. showed that lapatinib enhanced the effects of trastuzumab by inducing HER-2 stabilization and accumulation at the cell surface of breast cancer cell lines [24], and Mimura et al. reported that lapatinib induced accumulation of HER-2 and EGFR on esophageal cancer cell lines evoking trastuzumab- and cetuximab- mediated ADCC [25].

ADCC, one of the killing mechanism of the immune system mediated by Natural Killer cells, plays a pivotal role in the anti-cancer effects exerted by mAbs. Therefore, increasing the ADCC activity is an important objective in the development of novel therapeutic approaches.

It has been recently demonstrated that the EGFR inhibitors gefitinib and erlotinib enhance the susceptibility to NK cell mediated lysis of A549, NCI-H23 and SW900 lung cancer cell lines [26] by the induction of ULBP1 (a ligand of the NK cell activation receptor NKG2D). These data indicate that EGFR blockade could not be the only mechanism of action of EGFR inhibitors in vivo. The efficacy of these inhibitors in lung cancer may be at least in part mediated by increased susceptibility to NK activity. Moreover, cetuximab serves as a potent stimulus for NK functions including INF-gamma production [27] and is also associated with a complement -mediated immune response [28].

We here demonstrated that erlotinib induces an accumulation of EGFR and/or HER2 protein at the plasma membrane level only in TKI sensitive NSCLC cell lines whereas, in resistant cells (both, intrinsic or MET amplification-mediated acquired resistance), this enhancement was not observed. The anti-tumour effect of drug combination was more evident in ADCC experiments compared with cell viability experiments. In the Calu-3 xenograft model, the combined treatment resulted in a lower rate of tumour growth, suggesting the involvement of NK activity as a determinant factor to improve the efficacy of the combined treatment. Moreover, regressive phenomena and changes in size of neoplastic glands together with intense stromal reaction were observed in histologic samples of tumours from mice treated with cetuximab alone or the combination.
The reason why EGFR inhibitors such as gefitinib, erlotinib or lapatinib induce EGFR accumulation only in sensitive cells could be ascribed to their ability to inhibit signal transduction pathways downstream EGFR. The constitutive activation of signaling pathways downstream of EGFR (i.e. presence of RAS mutations) is indeed a recognized mechanism of resistance against reversible EGFR-TKIs [29]. The inhibition of the MAPK pathway might represent a link between EGFR inhibition and EGFR accumulation since U0126, a well known MEK1/2 inhibitor, induced EGFR accumulation in Calu-3 cells, while none of PI3K/AKT/mTOR inhibitors tested was effective. A correlation between MAPK pathway and protein degradation by the ubiquitin system was described for the pro-apoptotic BH3-only protein BIM, indeed in the absence of MAPK activation, BIM protein accumulated in the cell promoting activation of apoptotic cell death [30].

Considering that EGFR TKIs, in particular erlotinib, demonstrated to be effective only in a small percentage of NSCLC patients not harboring EGFR mutations, our preclinical results could support clinical trials on the combinations of erlotinib and cetuximab or trastuzumab aiming to improve treatment efficacy. Although the addition of cetuximab to erlotinib is insufficient to overcome erlotinib resistance in EGFR-driven lung adenocarcinoma [23], the clinical potential of dualagent molecular targeting of the EGFR in patients with EGFR wild-type tumours remains to be elucidated and may represents an interesting research area to be pursued.

\section{Conclusions}

In this study we explored the potential of combining erlotinib with cetuximab or trastuzumab in improving the efficacy of EGFR targeted therapy in EGFR wild-type erlotinib-sensitive NSCLC cell lines. Our results indicate that erlotinib, through ERK inhibition, increases surface expression of EGFR and/or HER2 only in erlotinib sensitive NSCLC cell lines and in turn leads to increased susceptibility to ADCC both in vitro and in xenografts models.

These data prompt future adequate clinical trials that will give the ultimate proof of the utility of this combined treatment for the care of NSCLC patients carrying EGFR-wild type that are sensitive to TKIs.

\section{Methods}

Cell culture

The human NSCLC cell lines H322, H292, Calu-3, H1299, A549, H1703 and Calu-1 were obtained from American Type Culture Collection (Manassas, VA, USA) and were cultured as recommended. The PC9, HCC827 and HCC827GR5 cell lines were kindly provided by Dr P. 
Jänne (Dana-Farber Cancer Institute, Boston MA, USA). All cells were maintained under standard cell culture conditions at $37^{\circ} \mathrm{C}$ in a water-saturated atmosphere of $5 \%$ $\mathrm{CO}_{2}$ in air. As previously reported [31] cells showing by proliferation assays $\mathrm{IC}_{50}$ for erlotinib $<1 \mu \mathrm{M}$ were considered sensitive (H322, H292, Calu-3, PC9, HCC827) while cell lines with $\mathrm{IC}_{50}>5 \mu \mathrm{M}$ (H1299, A549, H1703, Calu-1, HCC827GR5) were considered resistant.

\section{Drug treatment}

Erlotinib, gefitinib, cetuximab, trastuzumab and rituximab were from inpatient pharmacy. RAD001, NVP-BKM-120 and NVP-BYL-719 were from Novartis.

Stock solutions of $20 \mathrm{mM}$ drugs were prepared in dimethylsulfoxide (DMSO) (with the exception of $\mathrm{mAbs}$ ), stored at $-20^{\circ} \mathrm{C}$ and diluted in fresh medium for use. The final concentration of DMSO never exceeded $0.1 \% \mathrm{v} / \mathrm{v}$.

\section{Western blot analysis}

Procedures for protein extraction, solubilization, and protein analysis by 1-D PAGE are described elsewhere $[32,33]$. Fifty $\mu \mathrm{g}$ of proteins from lysates were resolved by $7.5 \%$ SDS-PAGE and transferred to PVDF membranes. Membranes were incubated with: 1:1000 rabbit polyclonal anti-EGFR; 1:1000 rabbit $\mathrm{mAb}$ anti-HER2/ ErbB2; 1:1000 rabbit $\mathrm{mAb}$ anti-Phospho-p70S6K (Thr421/Ser424); 1:1000 mouse mAb anti-Phospho-p44/ 42 MAPK (ERK1/2); 1:1000 rabbit mAb anti-p44/42 MAPK (ERK1/2) (Cell Signaling Technology, Beverly, MA, USA); 1:1000 mouse mAb anti- Transferrin Receptor (Invitrogen Corporation, Camarillo, CA, USA); 1:3000 mouse mAb anti-Actin (Sigma-Aldrich, St Louis, MO, USA). Blots were then washed and incubated with HRPanti-mouse or HRP-anti-rabbit antibodies at 1:20000 dilution (Pierce, Rockford, IL, USA). Immunoreactive bands were visualized using an enhanced chemiluminescence system (Immobilion ${ }^{\text {TM }}$ Western Cemiluminescent HRP Substrate, Millipore USA).

\section{Cell surface protein isolation}

Calu-3 cells were grown in T75 flasks and treated with $0.5 \mu \mathrm{M}$ erlotinib for $24 \mathrm{~h}$. Cells were incubated with EZ-LINK Sulfo-Biotin (Pierce) for $2 \mathrm{~h}$ at $4^{\circ} \mathrm{C}$ with gentle rotation. The reaction was stopped by washing twice with $25 \mathrm{mM}$ Tris- $\mathrm{HCl}$ (pH 7.5) in PBS (phosphate-buffered saline) and cells were scraped into ice-cold lysis buffer $(50 \mathrm{mmol} / \mathrm{l} \mathrm{HEPES,} \mathrm{pH} \mathrm{7.0,} \mathrm{10 \%} \mathrm{glycerol,} \mathrm{1 \%} \mathrm{Tri-}$ tonX-100, $5 \mathrm{mmol} / \mathrm{l}$ EDTA (ethylenediaminetetraacetic acid), $1 \mathrm{mmol} / \mathrm{l} \mathrm{MgCl}_{2}, 25 \mathrm{mmol} / \mathrm{l} \mathrm{NaF}, 50 \mu \mathrm{g} / \mathrm{ml} \mathrm{leu-}$ peptin, $50 \mu \mathrm{g} / \mathrm{ml}$ aprotinin, $0.5 \mathrm{mmol} / \mathrm{l}$ orthovanadate, and $1 \mathrm{mmol} / \mathrm{l}$ phenylmethylsulfonyl fluoride). Lysates were centrifuged at $15000 \mathrm{~g}$ for $20 \mathrm{~min}$ at $4^{\circ} \mathrm{C}$, and supernatants were removed and assayed for protein concentration using the DC Protein assay (Bio-Rad, CA, USA). A volume of $500 \mu$ l of lysis buffer containing equal amount of proteins was incubated with UltraLink Immobilized NeutrAvidin protein (Pierce) for $2 \mathrm{~h}$ at $4^{\circ} \mathrm{C}$ with gentle rotation, washed three times with lysis buffer before suspension in SDS (sodium dodecyl sulfate)-loading buffer and then resolved by SDS-PAGE.

\section{Flow cytometry}

For the determination of EGFR and HER2 protein membrane levels, NSCLC cell lines H322, Calu-3 and H292 were treated with $1 \mu \mathrm{M}$ erlotinib for $24 \mathrm{~h}$. One million cells per condition were then incubated with Isotype control Monoclonal Mouse IgG1/R-PE (Ancell IRP, Bayport, MN, USA), PE mouse anti-Human EGFR (Calu-3 and H322 cells) (BD Biosciences, San Josè, CA, USA) or PE mouse anti-Human HER2 (H322 and H292) (BD Biosciences). After the incubation the analysis was performed with an EPICS-XL flow cytometer.

For the relative quantization of EGFR or HER2 binding sites, NSCLC cell lines H322, Calu-3, H292 were treated with $1 \mu \mathrm{M}$ erlotinib for $24 \mathrm{~h}$. One million cells were then dispensed for each condition and treated with either $20 \mu \mathrm{g} / \mathrm{ml}$ rituximab (Isotype control), cetuximab (Calu-3 and H322) or trastuzumab (H292) for $1 \mathrm{~h}$. After the incubation with PE-anti-human-IgG (BD Biosciences), the analysis was performed with an EPICS-XL flow cytometer.

The values of mean fluorescence intensity (MFI) were converted in units of equivalent fluorochrome (MEF) using the FluoroSpheres 6-Peak Kit (Dako, CA, USA).

\section{Quantitative real-time PCR}

Total RNA was isolated by the TRIzol ${ }^{\circledR}$ reagent (Invitrogen, Carlsbad, CA, USA) and reverse transcribed as previously described [33].

The transcript levels of EGFR gene were assessed by Real-Time qRT-PCR on an iCycler iQ Multicolor RealTime PCR Detection System (Bio-Rad, Hercules, CA, USA).

Primers and probes included: EGFR-F (5'-GCCTT GACTGAGGACAGCA-3'), EGFR-R (5-TTTGGGAAC GGACTGGTTTA-3), EGFR-probe (5'-FAM CTTCC TCC3'DQ); PGK1-F (5'-GGAGAACCTCCGCTTTCAT3'), PGK1-R (5'-CTGGCTCGGCTTTAACCTT-3'), PGK1probe (5'-FAM GGAGGAAG $\left.3^{\prime} \mathrm{DQ}\right)$; RPL13-F (5'-AC AGCTGCTCAGCTTCACCT-3'), RPL13-R (5'-TGGCAG CATGCCATAAATAG-3'), RPL13-probe (5'-FAMCAGT GGCA3'DQ); HPRT-F (5'-TGACCTTGATTTATTTTGC ATACC-3'), HPRT-R (5'CGAGCAAGACGTTCAGTCC T-3'), HPRT-probe (5'-FAM GCTGAGGA $3^{\prime}$ DQ).

The amplification protocol consisted of $15 \mathrm{~min}$ at $95^{\circ} \mathrm{C}$ followed by 40 cycles at $94^{\circ} \mathrm{C}$ for 20 s and at $60^{\circ} \mathrm{C}$ for $1 \mathrm{~min}$. 
The relative transcript quantification was calculated using the geNorm algorithm for Microsoft Excel ${ }^{\mathrm{TM}}$ after normalization by expression of the control genes [phosphoglycerate kinase1 (PGK1), ribosomal protein L13 (RPL13) and hypoxanthine-guanine-phosphoribosyltransferase (HPRT)] and expressed in arbitrary units (a.u.).

\section{MTT assay}

The cells were seeded into 96-well plate in quadruplicate and were exposed to various treatments. After $96 \mathrm{~h}$, $100 \mu \mathrm{l}$ of 3-(4,5-dimethylthiazol-2-yl)-2,5 diphenyltetrazolium bromide (MTT) solution $(1 \mathrm{mg} / \mathrm{ml}$, SigmaAldrich) was added to each well and incubated. After $4 \mathrm{~h}$, crystalline formation was dissolved with DMSO and the absorbance at $570 \mathrm{~nm}$ was measured using the microplate-reader 550 (BioRad).

\section{Isolation and culture of NK cells}

Human PBMC were isolated from buffy coat of healthy donors by using a Lympholyte- $\mathrm{H}$ density gradient centrifugation (Cederlane Burlington, Ontario, Canada). Highly purified $\mathrm{CD}^{2} 6^{+}$natural killer (NK) cells were obtained by magnetic separation using the NK Cell Isolation Kit and the autoMACS Separator (Miltenyi Biotec, Cologne, Germany) according to the user manual.

Purified NK cells were resuspended in culture medium (RPMI 1640 without phenol red and supplemented with heat inactivated $10 \% \mathrm{FCS}, 50 \mathrm{U} / \mathrm{ml}$ penicillin, $50 \mathrm{U} / \mathrm{ml}$ streptomycin, $2 \mathrm{mmol} / \mathrm{l}$ glutamine) plated and preincubated at $37^{\circ} \mathrm{C}$ for up to $18 \mathrm{~h}$ in the presence of human Interleukin-2 (IL-2, $100 \mathrm{U} / \mathrm{ml}$, Miltenyi Biotec).

\section{ADCC assay}

Antibody-dependent cell-mediated cytotoxicity (ADCC) was measured with the CytoTox 96 non-radioactive cytotoxicity assay (Promega, Madison, WI, USA) according to manufacturer's instructions. $2 \times 10^{3}$ Calu-3, H322, H292 or H1299 cells were treated for $24 \mathrm{~h}$ with $1 \mu \mathrm{M}$ erlotinib, and then seeded with purified NK cells (ratio of 1:25 and 1:50) in a 96-well plate and incubated with $10 \mu \mathrm{g} / \mathrm{ml}$ cetuximab or trastuzumab. After 4 hours the lactate dehydrogenase (LDH) release was determined and the percentage of cytotoxicity was calculated after correcting for background absorbance values according to the following formula:

\section{Tumour xenografts}

All experiments involving animals and their care were performed with the approval of the Local Ethical Committee of University of Parma, in accordance with the institutional guidelines that are in compliance with national (DL116/92) and international (86/609/CEE) laws and policies. Twenty-four Balb/c-Nude female mice (Charles River Laboratories, Calco, Italy) were housed in a protected unit for immunodeficient animals with 12-hour light/dark cycles and provided with sterilized food and water ad libitum. At the time of xenograft establishment, mice were 8 weeks old and weighted $\sim 20 \mathrm{~g}$. $200 \mu \mathrm{l}$ of matrigel (BD Biosciences) and sterile PBS (1:1) containing $1 \times 10^{7}$ Calu-3 cells, were subcutaneously injected on the right flank of each mouse (using a $1 \mathrm{ml}$ syringe, needle G25). When tumour volume reached an average size of $300 \mathrm{~mm}^{3}, 14$ days after injection, animals were randomized into four groups and the treatment started. After 4 weeks, mice were euthanized by cervical dislocation and tumours collected for immunohistochemistry and histological analysis.

Erlotinib $(25 \mathrm{mg} / \mathrm{Kg})$ was administered orally in $1 \%$ methylcellulose, $0.2 \%$ Tween 80 in sterilized water 5 days/week. Cetuximab $(2 \mathrm{mg} / \mathrm{Kg})$ was intraperitoneally injected in sterile saline solution 2 days/week. Control group received both oral gavage of $1 \%$ methylcellulose, $0.2 \%$ Tween 80 in sterilized water 5 days/week and i.p. injection of sterile saline solution (0.9\%) 2 days/week.

Dosages of drugs were chosen halving the one used in a previous study in NSCLC-xenograft models, in order to avoid the complete inhibition of tumour growth by the single agent treatment and to better highlight the effect of erlotinib-cetuximab combination [19,34].

Tumour xenografts were measured twice a week, tumour volume was determined using the formula: $\left(\right.$ length $\mathrm{x}$ width $\left.{ }^{2}\right) / 2$. Final data are expressed as percent of volume increase: (tumour volume/pre-treatment tumour volume) x 100 .

\section{Morphometric and immunohistochemical analysis of tumour xenografts}

Formalin fixed samples were embedded in paraffin. From each tumour serial sections of $5 \mu \mathrm{m}$ thickness were obtained and stained with Haematoxylin and Eosin (H\&E), Masson's Trichrome and for immunohistochemistry. Morphometric analysis was performed in order to evaluate: (a) the numerical density of neoplastic cells, (b) the volume fraction of interstitial inflammatory cells, (c) the volume 
fraction of fibrosis and (d) the fraction of proliferating and apoptotic cells.

In particular, for each section stained with $\mathrm{H} \& \mathrm{E}$, a quantitative evaluation of tissue composition was performed. To better define the fraction occupied by neoplastic and non neoplastic cells, sections were stained with pancytokeratin antibodies (monoclonal mouse, 1:500, o.n. $4^{\circ} \mathrm{C}$, Dako) revealed through biotinstreptavidin-DAB system, as repeatedly described. The numerical density $\left(\mathrm{n} / \mathrm{mm}^{2}\right)$ of pancytokeratin positive neoplastic cells was computed.

In addition, cell proliferation and apoptotic death were investigated by fluorescence microscopy. Thus, Ki67 labeling (rabbit polyclonal antibody, Vector) and the Terminal deoxynucleotidyltransferase (TdT)-mediated dUTP nick end labeling (TUNEL) assay (Roche Diagnostics, Italy) on cytokeratin $^{\text {pos }}$ neoplastic cells were revealed by specific fuorescent probes.

The area occupied by interstitial cells was expressed as percentage of the total area explored. By the same approach, the volume fraction of fibrosis was calculated on Masson's Trichrome stained sections. To define the volume fractions, the number of points overlying each tissue components was counted and expressed as percentage of the total number of points explored.

All these morphometric measurements were obtained with the aid of a grid defining a tissue area of $0.23 \mathrm{~mm}^{2}$ and containing 42 sampling points each covering an area of $0.0052 \mathrm{~mm}^{2}$.

All these evaluations were performed on the entire section of each tumour sample of each experimental group of animals using an optical microscope (250X final magnification).

\section{Statistical analysis}

Statistical analyses were carried out using GraphPad Prism version 5.0 software (GraphPad Software Inc., San Diego, CA, USA). Results are expressed as mean values \pm standard deviations $(\mathrm{SD})$ for the indicated number of independent measurements. Differences between the mean values recorded for different experimental conditions were evaluated by Student's t-test, and $P$ values are indicated where appropriate in the figures and in their legends. A P value $<0.05$ was considered as significant.

For in vivo studies comparison among groups was made using analysis of variance (two-way ANOVA repeated measures) followed by Bonferroni's post-test. Analysis was performed using Prism 5.0 (GraphPad Software) and differences were considered significant when $\mathrm{P}$ value was below 0.05 . The nature of the interaction between erlotinib and cetuximab was calculated using the Bliss interaction model [35].

\section{Abbreviations}

ADCC: Antibody-dependent cellular-cytotoxicity; EGFR: Epidermal growth factor receptor; MAPK: Mitogen-activated protein kinase; NSCLC: Non small cell lung cancer; TKI: Tyrosine kinase inhibitor.

\section{Competing interest}

All authors declare that they have no competing interests.

\section{Authors' contribution}

AC carried out ADCC experiments, interpreted the results and assisted with the draft of the manuscript; DC isolated and cultured NK cells and carried out flow cytometry analysis; FS, LA and PC performed the in vivo studies; PM carried out RT-PCR experiments; MG and MB carried out Western blot analysis; EG performed the statistical analysis, SLM and CF carried out cell growth experiments; FQ, GG and DM carried out immunohistochemical analysis; AM, MT, EB and PGP critically revised the manuscript; AA designed the project and assisted with the draft of the manuscript; RRA, analyzed the results and wrote the manuscript. All authors read and approved the final manuscript.

\section{Acknowledgements}

This work was supported by: Associazione Italiana per la Ricerca sul Cancro (AIRC), Milan grant IG 8856; Associazione Augusto per la Vita (Novellara, RE); Associazione Davide Rodella, Montichiari, BS; Associazione Chiara Tassoni, Parma; A.VO.PRO.RI.T., Parma.

\section{Author details}

${ }^{1}$ Department of Clinical and Experimental Medicine, University of Parma, Parma, Italy. ${ }^{2}$ Department of Surgical Science, University of Parma, Parma, Italy. 'Italian Workers' Compensation Authority (INAIL) Research Center, University of Parma, Parma, Italy. ${ }^{4}$ Division of Medical Oncology, University Hospital of Parma, Parma, Italy. ${ }^{5}$ Department of Pharmacy, University of Parma, Parma, Italy.

Received: 30 August 2012 Accepted: 3 December 2012

Published: 12 December 2012

\section{References}

1. Schlessinger J: Ligand-induced, receptor-mediated dimerization and activation of EGF receptor. Cell 2002, 110:669-672.

2. Normanno N, De Luca A, Bianco C, Strizzi L, Mancino M, Maiello MR, Carotenuto A, De Feo G, Caponigro F, Salomon DS: Epidermal growth factor receptor (EGFR) signaling in cancer. Gene 2006, 366:2-16.

3. Hirsch FR, Varella-Garcia M, Bunn PA Jr, Di Maria MV, Veve R, Bremmes RM, Baron AE, Zeng C, Franklin WA: Epidermal growth factor receptor in non-small-cell lung carcinomas: correlation between gene copy number and protein expression and impact on prognosis. J Clin Oncol 2003, 21:3798-3807.

4. Liu L, Shao X, Gao W, Bai J, Wang R, Huang P, Yin Y, Liu P, Shu Y: The role of human epidermal growth factor receptor 2 as a prognostic factor in lung cancer: a meta-analysis of published data. J Thorac Oncol 2010, 5:1922-1932.

5. Shepherd FA, Rodrigues Pereira J, Ciuleanu T, Tan EH, Hirsh V, Thongprasert S, Campos D, Maoleekoonpiroj S, Smylie M, Martins R, et al: Erlotinib in previously treated non-small-cell lung cancer. N Engl J Med 2005, 353:23-132.

6. Cataldo VD, Gibbons DL, Perez-Soler R, Quintas-Cardama A: Treatment of non-small-cell lung cancer with erlotinib or gefitinib. N Engl J Med 2011, 364:947-955.

7. Douillard JY, Shepherd FA, Hirsh V, Mok T, Socinski MA, Gervais R, Liao ML, Bischoff H, Reck M, Sellers MV, et al: Molecular predictors of outcome with gefitinib and docetaxel in previously treated non-small-cell lung cancer: data from the randomized phase III INTEREST trial. J Clin Oncol 2010, 28:744-752.

8. Cappuzzo F, Ciuleanu T, Stelmakh L, Cicenas S, Szczesna A, Juhasz E, Esteban E, Molinier O, Brugger W, Melezinek I, et al: Erlotinib as maintenance treatment in advanced non-small-cell lung cancer: a multicentre, randomised, placebo-controlled phase 3 study. Lancet Oncol 2010, 11:521-529.

9. Mendelsohn J, Baselga J: Status of epidermal growth factor receptor antagonists in the biology and treatment of cancer. J Clin Oncol 2003, 21:2787-2799. 
10. Pirker R, Pereira JR, Szczesna A, von Pawel J, Krzakowski M, Ramlau R, Vynnychenko I, Park K, Yu CT, Ganul V, et al: Cetuximab plus chemotherapy in patients with advanced non-small-cell lung cancer (FLEX): an open-label randomised phase III trial. Lancet 2009, 373:1525-1531.

11. Lynch TJ, Patel T, Dreisbach L, McCleod M, Heim WJ, Hermann RC, Paschold E, lannotti NO, Dakhil S, Gorton S, et al: Cetuximab and first-line taxane/ carboplatin chemotherapy in advanced non-small-cell lung cancer: results of the randomized multicenter phase III trial BMS099. J Clin Oncol 2010, 28:911-917.

12. Pirker R, Pereira JR, von Pawel J, Krzakowski M, Ramlau R, Park K, de Marinis F, Eberhardt WE, Paz-Ares L, Storkel S, et al: EGFR expression as a predictor of survival for first-line chemotherapy plus cetuximab in patients with advanced non-small-cell lung cancer: analysis of data from the phase 3 FLEX study. Lancet Oncol 2012, 13:33-42.

13. Langer CJ, Stephenson $P$, Thor A, Vangel M, Johnson DH: Trastuzumab in the treatment of advanced non-small-cell lung cancer: is there a role? focus on eastern cooperative oncology group study 2598. J Clin Oncol 2004, 22:1180-1187.

14. Gatzemeier U, Groth G, Butts C, Van Zandwijk N, Shepherd F, Ardizzoni A, Barton C, Ghahramani P, Hirsh V: Randomized phase II trial of gemcitabine-cisplatin with or without trastuzumab in HER2-positive non-small-cell lung cancer. Ann Oncol 2004, 15:19-27.

15. Matar P, Rojo F, Cassia R, Moreno-Bueno G, Di Cosimo S, Tabernero J, Guzman M, Rodriguez S, Arribas J, Palacios J, Baselga J: Combined epidermal growth factor receptor targeting with the tyrosine kinase inhibitor gefitinib (ZD1839) and the monoclonal antibody cetuximab (IMC-C225): superiority over single-agent receptor targeting. Clin Cancer Res 2004, 10:6487-6501.

16. Engelman JA, Zejnullahu K, Mitsudomi T, Song Y, Hyland C, Park JO, Lindeman N, Gale CM, Zhao X, Christensen J, et al: MET amplification leads to gefitinib resistance in lung cancer by activating ERBB3 signaling. Science 2007, 316:1039-1043.

17. Huang S, Armstrong EA, Benavente S, Chinnaiyan P, Harari PM: Dual-agent molecular targeting of the epidermal growth factor receptor (EGFR): combining anti-EGFR antibody with tyrosine kinase inhibitor. Cancer Res 2004, 64:5355-5362

18. Nakamura H, Takamori S, Fujii T, Ono M, Yamana H, Kuwano M, Shirouzu K. Cooperative cell-growth inhibition by combination treatment with ZD1839 (Iressa) and trastuzumab (Herceptin) in non-small-cell lung cancer. Cancer Lett 2005, 230:33-46.

19. Friess T, Scheuer W, Hasmann M: Combination treatment with erlotinib and pertuzumab against human tumor xenografts is superior to monotherapy. Clin Cancer Res 2005, 11:5300-5309.

20. Kimura H, Sakai K, Arao T, Shimoyama T, Tamura T, Nishio K: Antibodydependent cellular cytotoxicity of cetuximab against tumor cells with wild-type or mutant epidermal growth factor receptor. Cancer Sci 2007, 98:1275-1280

21. Kim HP, Han SW, Kim SH, Im SA, Oh DY, Bang YJ, Kim TY: Combined lapatinib and cetuximab enhance cytotoxicity against gefitinib-resistant lung cancer cells. Mol Cancer Ther 2008, 7:607-615.

22. Regales L, Gong Y, Shen R, de Stanchina E, Vivanco I, Goel A, Koutcher JA, Spassova M, Ouerfelli O, Mellinghoff IK, et al: Dual targeting of EGFR can overcome a major drug resistance mutation in mouse models of EGFR mutant lung cancer. J Clin Invest 2009, 119:3000-3010.

23. Janjigian YY, Azzoli CG, Krug LM, Pereira LK, Rizvi NA, Pietanza MC, Kris MG, Ginsberg MS, Pao W, Miller VA, Riely GJ: Phase I/II trial of cetuximab and erlotinib in patients with lung adenocarcinoma and acquired resistance to erlotinib. Clin Cancer Res 2011, 17:2521-2527.

24. Scaltriti M, Verma C, Guzman M, Jimenez J, Parra JL, Pedersen K, Smith DJ, Landolfi S, Ramon Y, Cajal S, Arribas J, Baselga J: Lapatinib, a HER2 tyrosine kinase inhibitor, induces stabilization and accumulation of HER2 and potentiates trastuzumab-dependent cell cytotoxicity. Oncogene 2009, 28:803-814.

25. Mimura K, Kono K, Maruyama T, Watanabe M, Izawa S, Shiba S, Mizukami Y, Kawaguchi $Y$, Inoue M, Kono T, et al: Lapatinib inhibits receptor phosphorylation and cell growth and enhances antibody-dependent cellular cytotoxicity of EGFR- and HER2-overexpressing esophageal cancer cell lines. Int J Cancer 2011, 129:2408-2416.
26. Kim H, Kim SH, Kim MJ, Kim SJ, Park SJ, Chung JS, Bae JH, Kang CD: EGFR inhibitors enhanced the susceptibility to NK cell-mediated lysis of lung cancer cells. J Immunother 2011, 34:372-381.

27. Roda JM, Joshi T, Butchar JP, McAlees JW, Lehman A, Tridandapani S, Carson WE III: The activation of natural killer cell effector functions by cetuximab-coated, epidermal growth factor receptor positive tumor cells is enhanced by cytokines. Clin Cancer Res 2007, 13:6419-6428.

28. Hsu YF, Ajona D, Corrales L, Lopez-Picazo JM, Gurpide A, Montuenga LM Pio R: Complement activation mediates cetuximab inhibition of nonsmall cell lung cancer tumor growth in vivo. Mol Cancer 2010, 9:139.

29. Engelman JA, Janne PA: Mechanisms of acquired resistance to epiderma growth factor receptor tyrosine kinase inhibitors in non-small cell lung cancer. Clin Cancer Res 2008, 14:2895-2899.

30. Ley R, Balmanno K, Hadfield K, Weston C, Cook SJ: Activation of the ERK1/2 signaling pathway promotes phosphorylation and proteasomedependent degradation of the BH3-only protein. Bim. J Biol Chem 2003, 278:18811-18816.

31. La Monica S, Galetti M, Alfieri RR, Cavazzoni A, Ardizzoni A, Tiseo M, Capelletti M, Goldoni M, Tagliaferri S, Mutti A, et al: Everolimus restores gefitinib sensitivity in resistant non-small cell lung cancer cell lines. Biochem Pharmacol 2009, 78:460-468.

32. Cavazzoni A, Alfieri RR, Carmi C, Zuliani V, Galetti M, Fumarola C, Frazzi R, Bonelli M, Bordi F, Lodola A, et al: Dual mechanisms of action of the 5benzylidene-hydantoin UPR1024 on lung cancer cell lines. Mol Cancer Ther 2008, 7:361-370.

33. Alfieri RR, Galetti M, Tramonti S, Andreoli R, Mozzoni P, Cavazzoni A, Bonelli M, Fumarola C, La Monica S, Galvani E, et al: Metabolism of the EGFR tyrosin kinase inhibitor gefitinib by cytochrome P450 1A1 enzyme in EGFR-wild type non small cell lung cancer cell lines. Mol Cancer 2011, 10:143.

34. Steiner P, Joynes C, Bassi R, Wang S, Tonra JR, Hadari YR, Hicklin DJ: Tumor growth inhibition with cetuximab and chemotherapy in non-small cell lung cancer xenografts expressing wild-type and mutated epidermal growth factor receptor. Clin Cancer Res 2007, 13:1540-1551.

35. Bonelli MA, Fumarola C, Alfieri RR, La Monica S, Cavazzoni A, Galetti M, Gatti R, Belletti S, Harris AL, Fox SB, et al: Synergistic activity of letrozole and sorafenib on breast cancer cells. Breast Cancer Res Treat 2010, 124:79-88.

doi:10.1186/1476-4598-11-91

Cite this article as: Cavazzoni et al:: Combined use of anti-ErbB monoclonal antibodies and erlotinib enhances antibody-dependent cellular cytotoxicity of wild-type erlotinib-sensitive NSCLC cell lines. Molecular Cancer 2012 11:91.

\section{Submit your next manuscript to BioMed Central and take full advantage of:}

- Convenient online submission

- Thorough peer review

- No space constraints or color figure charges

- Immediate publication on acceptance

- Inclusion in PubMed, CAS, Scopus and Google Scholar

- Research which is freely available for redistribution 